\title{
Review: chemotherapy and hormonal therapy reduce recurrence and mortality at 15 years in early breast cancer
}

Early Breast Cancer Trialists' Collaborative Group. Effects of chemotherapy and hormonal therapy for early breast cancer on recurrence and 15-year survival: an overview of the randomised trials. Lancet 2005;365:1687-717.

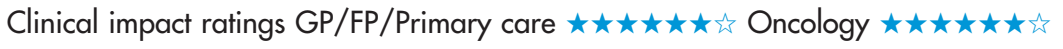

What are the effects of adjuvant chemotherapy, tamoxifen, and ovarian ablation or suppression on recurrence and survival 15 years after diagnosis of early breast cancer?

\section{METHODS}

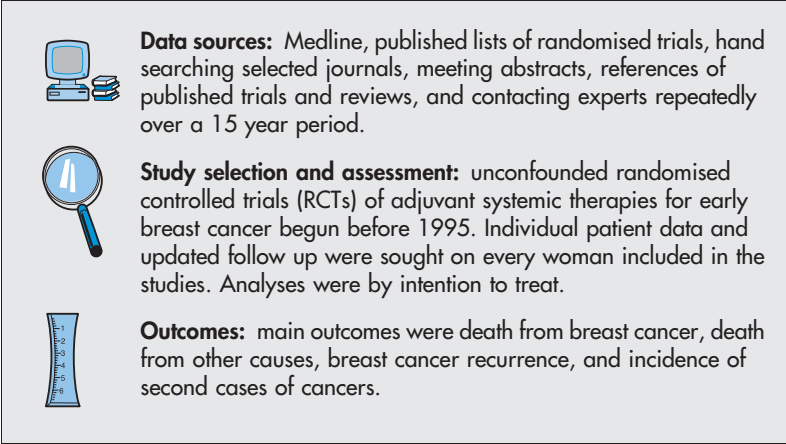

\section{MAIN RESULTS}

194 RCTs ( $\mathrm{n}=144939$ ) were included and comprise about $91 \%$ of all women randomised in such trials before 2000. Standard polychemotherapy, including an anthracycline for 4-6 months (eg, fluorouracil, cyclophosphamide, and either doxorubicin [adriamycin] or epirubicin [FAC or FEC]) reduced annual breast cancer mortality rates by $38 \%$ in women $<50$ years and by $20 \%$ in women $50-69$ years (table), and was more effective than cyclophosphamide, methotrexate, and fluorouracil (CMF) $(\mathrm{p}<0.001)$. These effects were independent of axillary lymph node involvement, oestrogen-receptor (ER) status, and treatment with tamoxifen. The absolute benefit of adjuvant chemotherapy at 15 years was more than double its benefit at 5 years in women $<50$ years of age (table). Tamoxifen for 5 years in women with ER positive disease reduced the annual breast cancer mortality rate by $31 \%$ and was more effective than tamoxifen for 1 or 2 years $(\mathrm{p}<0.001)$. These effects were independent of age, menopausal status, lymph node involvement, and tumour size. The absolute benefit of tamoxifen at 15 years was more than double its benefit at 5 years (table). Tamoxifen was ineffective in women with ER negative disease. Ovarian ablation or suppression reduced the annual breast cancer mortality rate by $29 \%$ in the absence of chemotherapy. Deaths from causes other than breast cancer were not affected by any of the 3 treatments.

For correspondence: EBCTCG Secretariat, CTSU, Radcliffe Infirmary, Oxford, UK. bc.overview@ctsu.ox.ac.uk

Source of funding: UK Medical Research Council.

\section{CONCLUSION}

Adjuvant chemotherapy, tamoxifen, and ovarian ablation or suppression substantially reduce mortality rates over 15 years in women with early breast cancer.

Abstract and commentary also appear in ACP Journal Club.

\section{Commentary}

$T$ he EBCTCG update of previous work shows that the survival benefits of adjuvant therapy persist over time-the effect of killing or suppressing micrometastases lasts far beyond the end of treatment. In this case, the absolute benefit can be as high as 10 additional women alive per 100 treated, with no additional deaths from treatment related diseases.

These are the minimal effects of adjuvant therapy, too, because current treatments are more effective and less toxic. Recent large RCTs show that the addition of paclitaxel to 4 cycles of doxorubicin-cyclophosphamide adds another 2-3 survivors per 100 women. ${ }^{1}$ We can add 2-3 more survivors by giving the same chemotherapy every 2 weeks instead of every 3 weeks. ${ }^{2}$ The addition of trastuzumab (Herceptin) for women whose cancer over expresses human epidermal growth factor receptor-2 may provide even more benefit, based on its substantial effects on disease free survival. ${ }^{3}$ A low fat diet (about $30 \mathrm{~g} / \mathrm{d}$ ) may reduce relative recurrence risk a further $24 \%$ when added to these "best" therapies. ${ }^{4}$ Aromatase inhibitors improve disease free survival more than tamoxifen alone, or when given after tamoxifen, and will probably improve overall survival. $^{5}$

How does one keep up with these developments? Adjuvant! (www.adjuvantonline.com) is a simple prediction tool to estimate the absolute benefits for women considering these treatments.

Thomas J Smith, MD James Khatcheressian, MD Virginia Commonwealth University Richmond, Virginia, USA

1 Henderson IC, Berry DA, Demetri GD, et al. J Clin Oncol 2003;21:976-83.

2 Citron ML, Berry DA, Cirrincione C, et al. J Clin Oncol 2003;21:1431-9.

3 Herceptin combined with chemotherapy improves disease survival for patients with early-stage breast cancer. National Cancer Institute. www.cancer.gov/newscenter/pressreleases/HerceptinCombination2005 (accessed 11 Oct 2005).

4 Chlebowski RT, Blackburn GL, Elashoff RE, et al. Dietary fat reduction in postmenopausal women with primary breast cancer: Phase III Women's Intervention Nutrition Study (WINS). American Society of Clinical Oncology Annual Meeting, 2005. www.asco.org/ac/1,1003, 12-002627-00 180034-00_19-0031414-00_30-001,00.asp (accessed 11 Oct 2005).

5 Howell A, Cuzick J, Baum M, et al. Lancet 2005;365:60-2.

Chemotherapy and tamoxifen for breast cancer at 15 years*

\begin{tabular}{|c|c|c|c|c|c|c|}
\hline \multirow{2}{*}{ Treatment } & \multirow{2}{*}{ Patient group } & \multirow{2}{*}{$\begin{array}{l}\text { Annual rate ratio for } \\
\text { breast cancer mortality } \\
\text { over } 15 y\end{array}$} & \multicolumn{3}{|c|}{ Absolute improvement in breast cancer mortality } & \multirow{2}{*}{$\mathrm{p}$ Value } \\
\hline & & & $5 y$ & $10 y$ & $15 y$ & \\
\hline $\begin{array}{l}\text { Polychemotherapy for } 4-6 \text { months } \\
\text { including an anthracycline }\end{array}$ & $\begin{array}{l}\text { Women }<50 y \\
\text { Women } 50-60 \text { y }\end{array}$ & $\begin{array}{l}0.62 \\
0.80\end{array}$ & $\begin{array}{l}4.7 \% \\
2.6 \%\end{array}$ & $\begin{array}{l}7.9 \% \\
2.9 \%\end{array}$ & $\begin{array}{l}10 \% \\
3.0 \%\end{array}$ & $\begin{array}{l}<0.001 \\
<0.001\end{array}$ \\
\hline Tamoxifen for $5 y$ & $\begin{array}{l}\text { Women with ER positive } \\
\text { disease (any age) }\end{array}$ & 0.69 & $3.6 \%$ & $7.9 \%$ & $9.2 \%$ & $<0.001$ \\
\hline
\end{tabular}

*ER = oestrogen receptor 